October 2002 - NREL/SR-560-32500

\title{
State Electricity Regulatory Policy and Distributed Resources: Distribution System Cost Methodologies for Distributed Generation
}

W. Shirley, R. Cowart, R. Sedano, F. Weston, C. Harrington, and D. Moskovitz The Regulatory Assistance Project Gardiner, Maine Montpelier, Vermont

\section{NPEI}

National Renewable Energy Laboratory

1617 Cole Boulevard

Golden, Colorado 80401-3393

NREL is a U.S. Department of Energy Laboratory

Operated by Midwest Research Institute $\bullet$ Battelle $\bullet$ Bechtel

Contract No. DE-AC36-99-G010337 


October $2002 \quad$ NREL/SR-560-32500

State Electricity Regulatory
Policy and Distributed
Resources:
Distribution System Cost
Methodologies for
Distributed Generation

W. Shirley, R. Cowart, R. Sedano, F. Weston,

C. Harrington, and D. Moskovitz

The Regulatory Assistance Project

Gardiner, Maine

Montpelier, Vermont

NREL Technical Monitor: Thomas Basso

Prepared under Subcontract No. NAD-1-30605-03

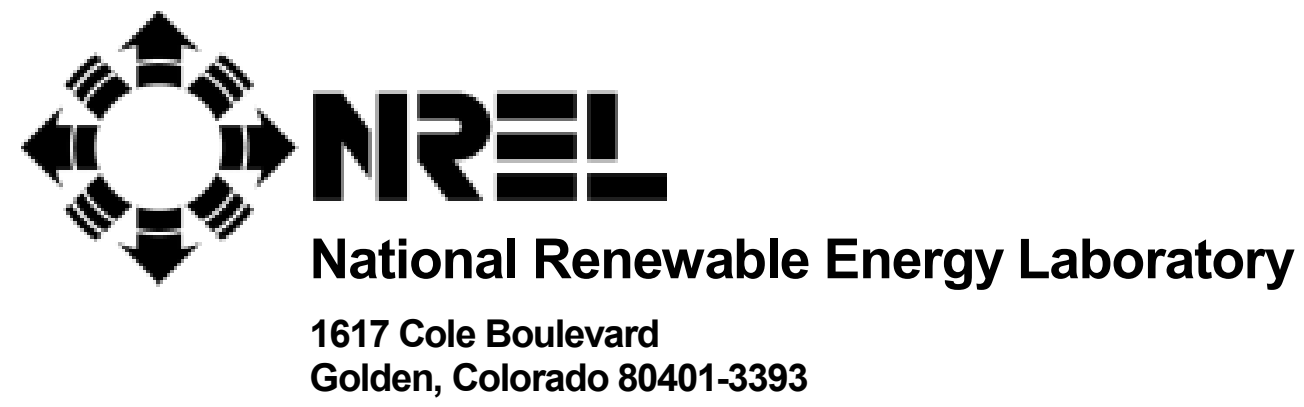

NREL is a U.S. Department of Energy Laboratory

Operated by Midwest Research Institute $\bullet$ Battelle $\bullet$ Bechtel

Contract No. DE-AC36-99-G010337 


\section{NOTICE}

This report was prepared as an account of work sponsored by an agency of the United States government. Neither the United States government nor any agency thereof, nor any of their employees, makes any warranty, express or implied, or assumes any legal liability or responsibility for the accuracy, completeness, or usefulness of any information, apparatus, product, or process disclosed, or represents that its use would not infringe privately owned rights. Reference herein to any specific commercial product, process, or service by trade name, trademark, manufacturer, or otherwise does not necessarily constitute or imply its endorsement, recommendation, or favoring by the United States government or any agency thereof. The views and opinions of authors expressed herein do not necessarily state or reflect those of the United States government or any agency thereof.

Available electronically at http://www.osti.gov/bridge

Available for a processing fee to U.S. Department of Energy

and its contractors, in paper, from:

U.S. Department of Energy

Office of Scientific and Technical Information

P.O. Box 62

Oak Ridge, TN 37831-0062

phone: 865.576.8401

fax: 865.576.5728

email: reports@adonis.osti.gov

Available for sale to the public, in paper, from:

U.S. Department of Commerce

National Technical Information Service

5285 Port Royal Road

Springfield, VA 22161

phone: 800.553.6847

fax: 703.605.6900

email: orders@ntis.fedworld.gov

online ordering: http://www.ntis.gov/ordering.htm 


\section{Foreword}

This report is one in a series of four that discusses aspects of state regulatory policy and the potential development of cost-effective distributed resources. These reports were prepared by The Regulatory Assistance Project under contract to the National Renewable Energy Laboratory (see Annual Technical Status Report of the Regulatory Assistance Project: September 2000September 2001, NREL/SR-560-32733). The work is a part of a larger U.S. Department of Energy initiative designed to further the development and safe and reliable deployment of distributed resources within the nation's electricity system.

Distributed resources offer many economic and reliability benefits to customers, utilities, and society as a whole. But in some very important ways, our state regulatory practices inadvertently have made it difficult for these resources to be deployed. Understanding the existing regulatory barriers may lead to their removal. States such as Texas, New York, California, and others have already undertaken new regulatory approaches that simplify the technical integration of distributed resources into their local distribution networks. We encourage regulators and interested parties to become familiar with the work now under way in these states and to take steps to ease the integration of small-scale resources into local distribution systems.

The papers in the State Regulatory Policy and Distributed Resources series may be found at www.nrel.gov/publications under the following titles:

- $\quad$ Accommodating Distributed Resources in Wholesale Markets, NREL/SR-560-32497

- Distributed Resource Distribution Credit Pilot Programs - Revealing the Value to Consumers and Vendors, NREL/SR-560-32499

- $\quad$ Distributed Resources and Electric System Reliability, NREL/SR-560-32498

- $\quad$ Distribution System Cost Methodologies for Distributed Generation, NREL/SR-56032500

- Distribution System Cost Methodologies for Distributed Generation Appendices, NREL/SR-560-32501.

These reports, along with previous reports that address related distributed resource issues, can also be accessed on line at www.raponline.org. 


\section{Preface}

The author would like to acknowledge the help of Tom Stanton of the Michigan Public Service Commission for critiques, suggestions, and review of this paper. 


\section{Table of Contents}

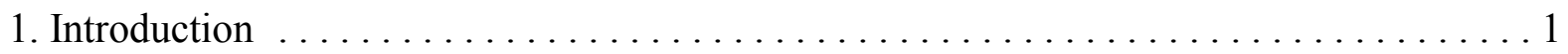

2. The Components of Distribution Costs $\ldots \ldots \ldots \ldots \ldots \ldots \ldots \ldots \ldots \ldots \ldots \ldots \ldots \ldots \ldots \ldots$

3. Embedded Costs for U.S. Utilities $\ldots \ldots \ldots \ldots \ldots \ldots \ldots \ldots \ldots \ldots \ldots \ldots \ldots$

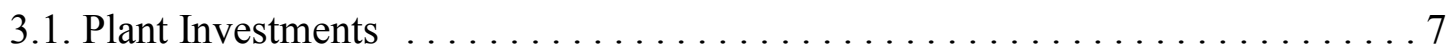

3.2. Transformers and Substation Embedded Plant Investment $\ldots \ldots \ldots \ldots \ldots \ldots 9$

3.3. Lines and Feeders Embedded Plant Investment . . . . . . . . . . . . 11

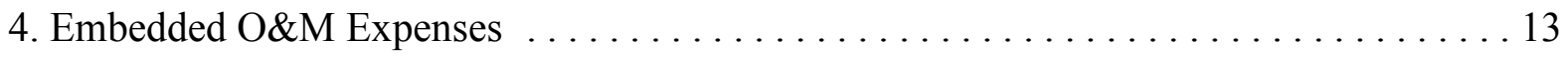

4.1. Transformer and Substation Embedded O\&M Expense . . . . . . . . . . 13

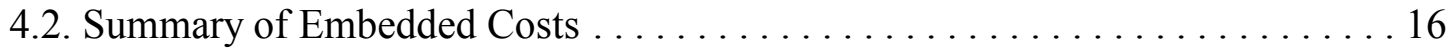

5. Marginal Costs . . . . . . . . . . . . . . . . . . . . . . . 19

6. The Relation of Growth in Investment to Growth in Company Size . . . . . . . . . . 21

6.1. Growth in Transformer and Substation Plant Investment . . . . . . . . . . 21

6.2. Growth in Lines and Feeders Investment $\ldots \ldots \ldots \ldots \ldots \ldots \ldots \ldots \ldots \ldots$

7. Relationship of Growth in Investment to System Growth Rates . . . . . . . . . . . 23

7.1. Marginal Cost of Transformers and Substations Plant . . . . . . . . . 24

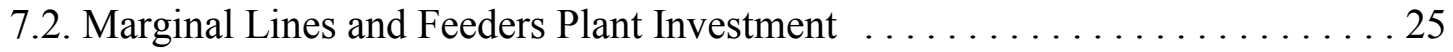

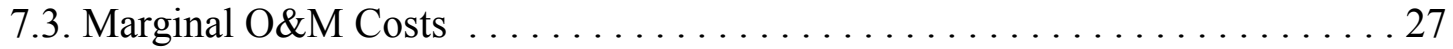

8. General Discussion of Marginal Cost Data . . . . . . . . . . . . . . . . . 29

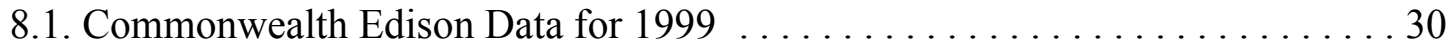

8.1.1. Timing Is As Important As Geography . . . . . . . . . . . . . . . 32

8.1.2. Distribution System Upgrade Strategies . . . . . . . . . . . . . . 34

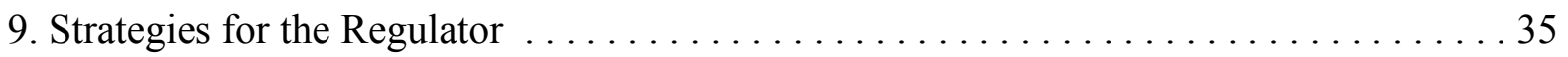

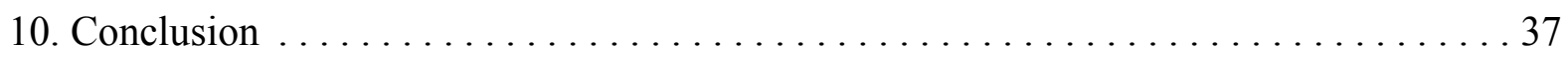

Appendices $\ldots \ldots \ldots \ldots \ldots \ldots \ldots \ldots \ldots \ldots \ldots \ldots \ldots \ldots \ldots \ldots \ldots \ldots \ldots \ldots$ See Volume II 


\section{Introduction}

The increased availability and decreasing costs of distributed resources (DR), or small-scale generation and efficiency resources, present new challenges in the regulation of distribution utilities. A key requirement in assessing DR is a working understanding of the cost of distribution systems and of the alternative costs that might be incurred or avoided in the absence or presence of DR. Because many of the choices to install DR will be largely decentralized, every effort should be made to reveal these costs to as many of the stakeholders as possible, including distribution utilities, customers, DR purveyors, Independent System Operators (ISOs) and system planners. It is equally important to reveal these costs to regulators who are in the position to see the big picture and develop appropriate policies for encouraging or discouraging DR, as necessary.

Distribution system costs have not historically received a high level of scrutiny by regulators. However, there is every reason to believe that the growth in investment in the distribution system is likely to accelerate over the next several years, raising the efficacy of greater regulatory review. Principal causes for the growth in distribution plant investments and costs include the deterioration of embedded facilities that are at or near the end of their useful lives, expansion and upgrade of facilities that operate at or near their capacity, and continued growth, both geographically and in terms of intensity, of consumer demand. Improvements in efficiency are unlikely to counterbalance this growth.

While generating costs may experience a decline through technological gains in efficiency, costs of the distribution system have no comparable innovations in the wings. Average aggregate annual investments of more than $\$ 6.4$ billion per year were made by the 124 utilities in our study. This translates into an annual revenue requirement increase per year on the order of $\$ 1$ billion to $\$ 1.5$ billion. This is a significant cost and deserves the attention of regulators and the application of appropriate least-cost strategies. To put this in context, the124 companies in our study had a total average revenue during the 1995-1999 period of just more than $\$ 134$ billion.

While the analysis here cannot provide the basis for making individual choices for specific projects, it does clearly demonstrate that there are many opportunities to implement distributed resources in lieu of traditional wires and transformers solutions. This study should provide the regulator with some guidelines about the important aspects of distribution costs and a framework for assessing the avoided costs of the distribution system.

This paper focuses on the actual costs of distribution utilities in the United States. We have drawn from a number of sources for this analysis. The principal source of data for this paper is the Federal Energy Regulatory Commission (FERC) Form 1 database for the years 19941999. Also, we have drawn upon individual case studies to demonstrate the significant deviation between particular distribution expansion costs and average marginal and average embedded costs. 


\section{The Components of Distribution Costs}

As a beginning point, we analyzed the average embedded and average marginal costs for 124 U.S. utilities for the period 1995-1999. ${ }^{1}$ The first step in this process is to determine which accounts should be analyzed and then group those into useful categories. Table 1 shows the FERC uniform distribution plant-in-service accounts, as reported in the FERC Form 1.

Table 1

\begin{tabular}{|l|}
\hline \multicolumn{1}{|c|}{ FERC Distribution Accounts } \\
(360) Land and Land Rights \\
(361) Structures and Improvements \\
(362) Station Equipment \\
(363) Storage Battery Equipment \\
(364) Poles, Towers, and Fixtures \\
(365) Overhead Conductors and Devices \\
(366) Underground Conduit \\
(367) Underground Conductors and Devices \\
(368) Line Transformers \\
(369) Services \\
(370) Meters \\
(371) Installations on Customer Premises \\
(372) Leased Property on Customer Premises \\
(373) Street Lighting and Signal Systems
\end{tabular}

Most distribution system construction projects fall into one of four categories:

- Improvements or expansion of transformers and substations

- Improvements or expansion of distribution lines and feeders

- $\quad$ Customer-specific equipment

- $\quad$ Other activities, such as street lighting and signal systems.

With this in mind, the FERC accounts can be grouped as follows:

- $\quad$ Transformer and substation investments (a portion of accounts 360 and 361 plus account 362)

${ }^{1}$ We began with the entire FERC Form 1 database for the years 1994-1999. Data for the 1994 was used only where needed to compute growth values for 1995. Many of the reporting utilities do not have distribution plant and so were excluded from the group used for this analysis. In addition, a number of utilities were excluded because they had incomplete data in the available database. The resulting data set includes 124 utilities. The included utilities are listed in Appendix A. 
- $\quad$ Lines and feeders investments (the balance of accounts 360 and 361 plus accounts $363,364,365,366,367$ and 368)

- $\quad$ Customer-specific investments (accounts 369, 370, 371 and 372)

- $\quad$ Street lighting and signal systems (account 373).

For purposes of the costs that might be avoided or deferred through the use of DR, only accounts 360 through 368 are of interest. With exception of accounts 360 and 361, most of the accounts clearly are related to specific types of distribution plant. Accounts 360 and 361 represent costs incurred for both transformers and substations and for lines and feeders. We assigned $25 \%$ of these accounts to transformers and substations and $75 \%$ of these accounts to lines and feeders.

In addition to investments in plant-in-service, we analyzed the associated operations and maintenance (O\&M) expenses for lines and feeders and for transformers and substations. The FERC uniform distribution O\&M expense accounts are reflected in Table 2.

Table 2

\begin{tabular}{|l|}
\hline \multicolumn{1}{|c|}{ FERC Form 1 Distribution Expenses } \\
\hline Operation \\
(580) Operation Supervision and Engineering \\
(581) Load Dispatching \\
(582) Station Expenses \\
(583) Overhead Line Expenses \\
(584) Underground Line Expenses \\
(585) Street Lighting and Signal System Expenses \\
(586) Meter Expenses \\
(587) Customer Installations Expenses \\
(588) Miscellaneous Expenses \\
(589) Rents \\
Maintenance \\
(590) Maintenance Supervision and Engineering \\
(591) Maintenance of Structures \\
(592) Maintenance of Station Equipment \\
(593) Maintenance of Overhead Lines \\
(594) Maintenance of Underground Lines \\
(595) Maintenance of Line Transformers \\
(596) Maintenance of Street Lighting and Signal Systems \\
(597) Maintenance of Meters \\
(598) Maintenance of Miscellaneous Distribution Plant \\
\hline
\end{tabular}


Accounts 582 and 592 were assigned directly to transformers and substations. Accounts 583, 584, 593 and 594 were assigned directly to lines and feeders. Account 591 was assigned 25\% to transformers and substations and $75 \%$ to lines and feeders, consistent with the allocation of the corresponding plant in service accounts. Finally, Account 580 was assigned $25 \%$ to transformers and substations and 50\% to lines and additions, with the assumption that the remaining $25 \%$ would be associated with the other distribution expenses categories (meters, customer installations, street lighting, etc.). While a more detailed study for a particular company might result in different assignments, these allocations provide a reasonable proxy for purposes of this paper. 


\section{Embedded Costs for U.S. Utilities}

A review of the FERC Form 1 data reveals that distribution system investments vary significantly from year to year for any given utility. As a result, any one year might distort the experience of each utility.

For this analysis, we collected the data for the 5 years 1995-1999 and computed the average additions to plant in service for each FERC account.

\subsection{Plant Investments}

What drives distribution plant investment?

We reviewed the relationship of investment in transformers and substations and lines and feeders to system peak, system sales, number of

Chart 1

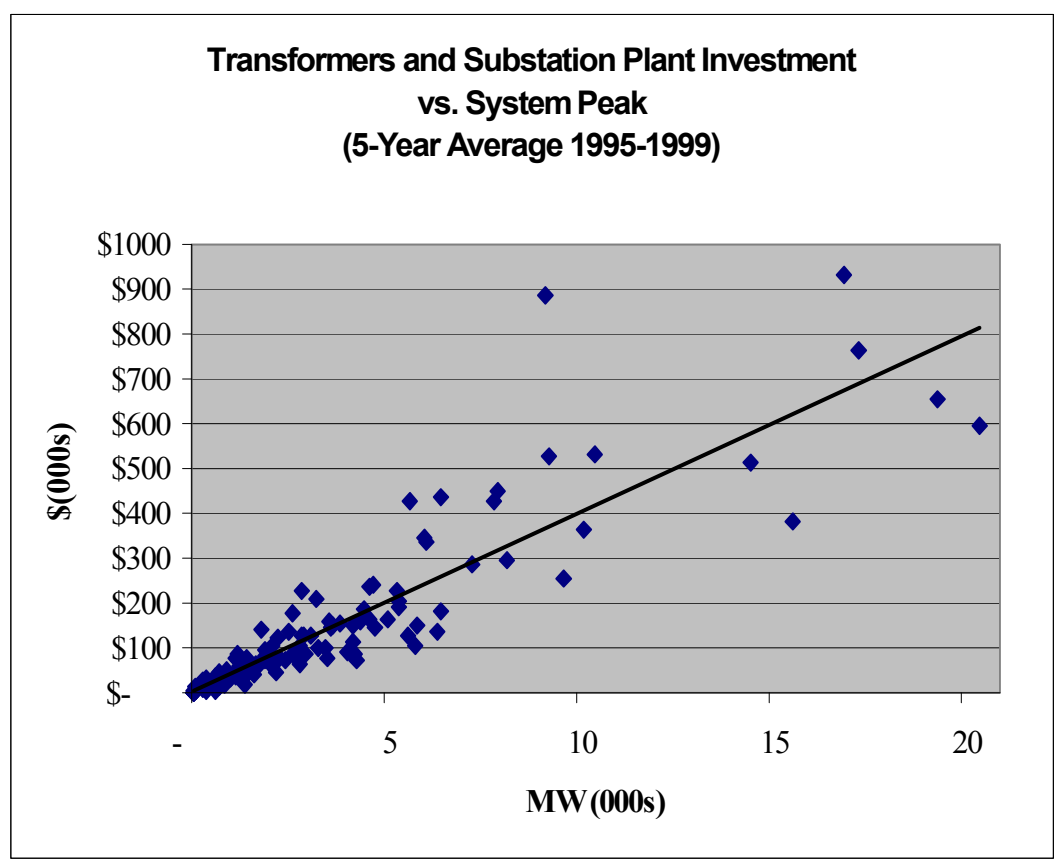
customers, and to overall system size. Using the 5-year average investment, system peak, system sales, and number of customer data, it becomes clear that the investment in transformers and substations and in lines and feeders are highly correlated with system peak and number of customers and somewhat less correlated with system sales.

Chart 1 shows data for transformers and substations compared to system peak, along with a linear trend-line plot. Even a casual study of this chart reveals the relationship between transformers and substations and system peak.

The $\mathrm{R}^{2}$ for transformers and substation plant investment and system peak is 0.89 , indicating a very strong correlation. Similarly, lines and feeders and system peak also exhibit a strong correlation with an $\mathrm{R}^{2}$ of .89 . Correlations of investment with the customers show even higher $\mathrm{R}^{2}$ values of 0.96 and 0.97 , for transformers and substations and lines and feeders, respectively. When compared to system energy, the $\mathrm{R}^{2}$ drops significantly to only .49 and .42 for transformers and substations and for lines and feeders, respectively. 
Even though costs show a higher correlation to number of customers, system expansions are usually engineered on the basis of peak demand and not directly on the number of customers. A review of actual distribution system plant expansion and upgrade projects considered by Commonwealth Edison in 1999, showed that the projects were analyzed and sized on the basis of peak demand.

We also analyzed the relation-ship of overall system size, in terms of both system peak and system energy to investment per megawatt (MW) of system peak. That is, do plant investments per MW go up or down as a function of the overall size of the utility? There was virtually no correlation between cost per MW and overall system size. Indeed, no significant economies of scale are apparent from the data. For example, trend lines for lines and feeders investment per MW of system peak show only a slight negative correlation $\left(\mathrm{R}^{2}\right.$ value) of -0.079 when compared to system peak. There is virtually no correlation between system size and investment per MW. High distribution costs can occur in small as well as large utilities. The comparable analysis for Transformers and

\section{Lines and Feeders Per MW \\ vs. System Peak \\ (5-Year Average 1995-1999)}

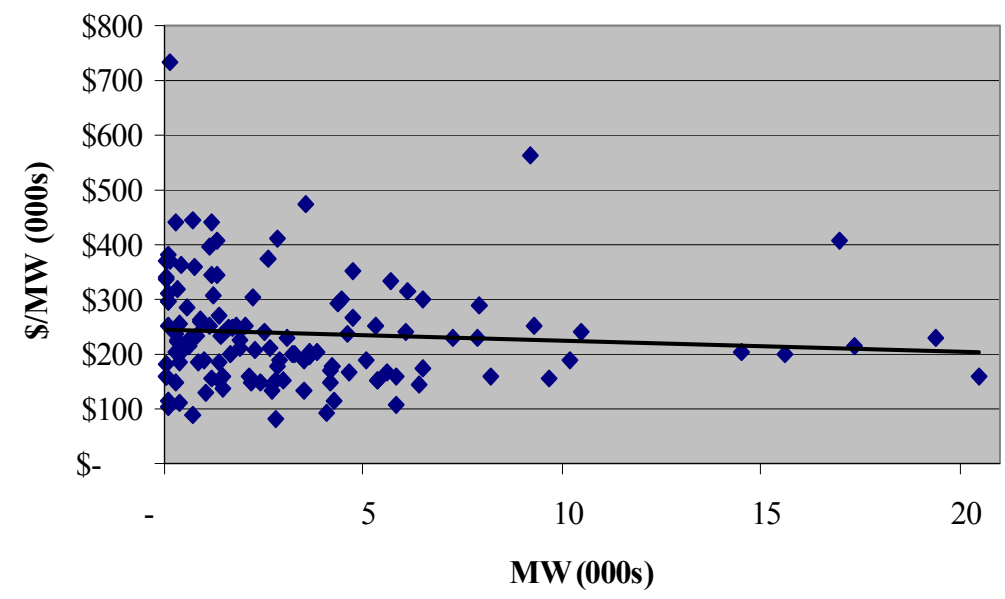

Lines \& Feeders Plant Investment Per Customer

vs. Number of Customers

(5 Yr. Average 1995-1999)

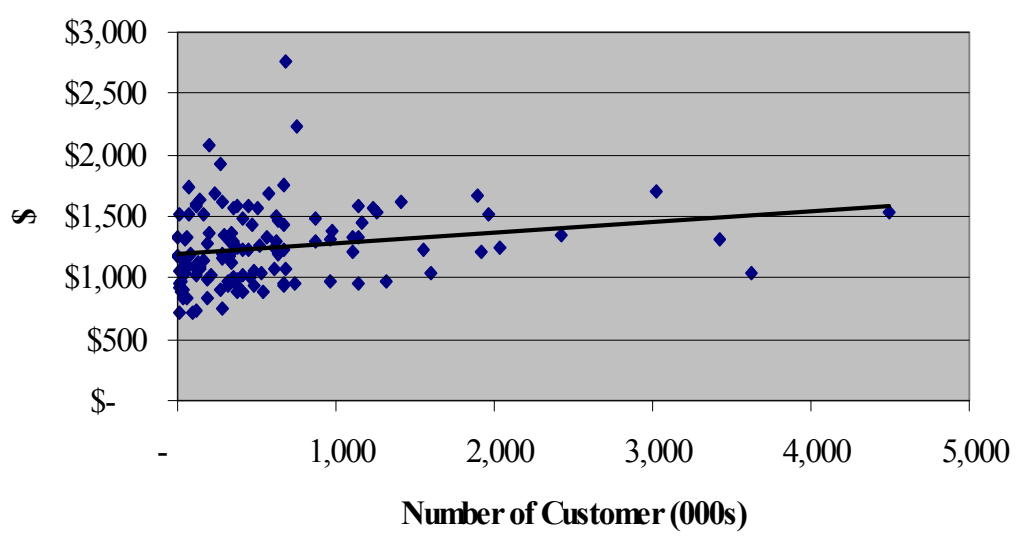

Chart 3 
Substations shows a correlation value of 0.099. Larger utilities exhibit little economies of scale in terms of investment efficiency, at least in terms of system peak and system energy.

On the other hand, in the case of lines and feeders plant investment, there is a slightly stronger correlation of costs with number of customers, where the $\mathrm{R}^{2}$ is .20 . This indicates a moderate relationship between investment per customer and the overall number of customers. As utilities get larger in terms of number of customers, their investment per customer tends to rise.

Chart 3 reflects this data for lines and feeders, along with a trend line plot.

\subsection{Transformers and Substation Embedded Plant Investment}

Table 3 shows the average embedded investment in transformers and substations per MW of average system peak for the five highest cost and five lowest cost utilities.

Table 3

\section{Average Transformers and Substations Plant Investment Per Average System Peak} (1995-1999)

\begin{tabular}{|c|c|c|}
\hline Rank & Company & $\begin{array}{c}\text { Transformers } \\
\text { and } \\
\text { Substations } \\
\text { Plant Per MW } \\
\text { of System } \\
\text { Peak }\end{array}$ \\
\hline 1 & Newport Electric Corporation & $\$ 134,768$ \\
\hline 2 & CambriDRe Electric Light Company & $\$ 101,817$ \\
\hline 3 & Consolidated Edison Company of New York, Inc. & $\$ 96,377$ \\
\hline 4 & Chugach Electric Association, Inc. & $\$ 82,719$ \\
\hline 5 & Boston Edison Company & $\$ 79,773$ \\
\hline & Average & $\$ 43,063$ \\
\hline 120 & Ohio Power Company & $\$ 17,830$ \\
\hline 121 & Indiana Michigan Power Company & $\$ 16,972$ \\
\hline 122 & Kingsport Power Company & $\$ 14,780$ \\
\hline 123 & Public Service Company of New Hampshire & $\$ 12,216$ \\
\hline 124 & Madison Gas and Electric Company & $\$ 6,712$ \\
\hline \multicolumn{3}{|c|}{ Statistical Summary } \\
\hline & Standard Deviation & $\$ 18,903$ \\
\hline & Average & $\$ 43,063$ \\
\hline & Correlation & 0.89 \\
\hline & Average Plus Standard Deviation & $\$ 61,966$ \\
\hline & Average Less Standard Deviation & $\$ 24,160$ \\
\hline
\end{tabular}


The deviation from the average for the lowest and highest cost utilities is fairly dramatic ranging from approximately $1 / 7$ of the average for the lowest cost utility to more than three times the average for the highest cost utility. In addition, the standard deviation for the group is approximately $\$ 19,000$, meaning that approximately $68 \%$ of the utilities are in the range from approximately half of the average to roughly 1.5 times the average. This is a relatively large spread, indicating the need to consider individual utility circumstances carefully.

Chart 4 reflects the distribution of embedded plant investment per MW for transformers and substations grouped in $\$ 2,500$ increments. The dispersion of costs across a wide range is apparent from this chart. While 98 out of 124 of the companies experience costs between $\$ 22,000$ and $\$ 57,500$ per $\mathrm{MW}$, this is still a substantial range of costs.

\section{Chart 4}

\section{Distribution of Transformers \& Substations Plant Investment Per MW of System Peak}

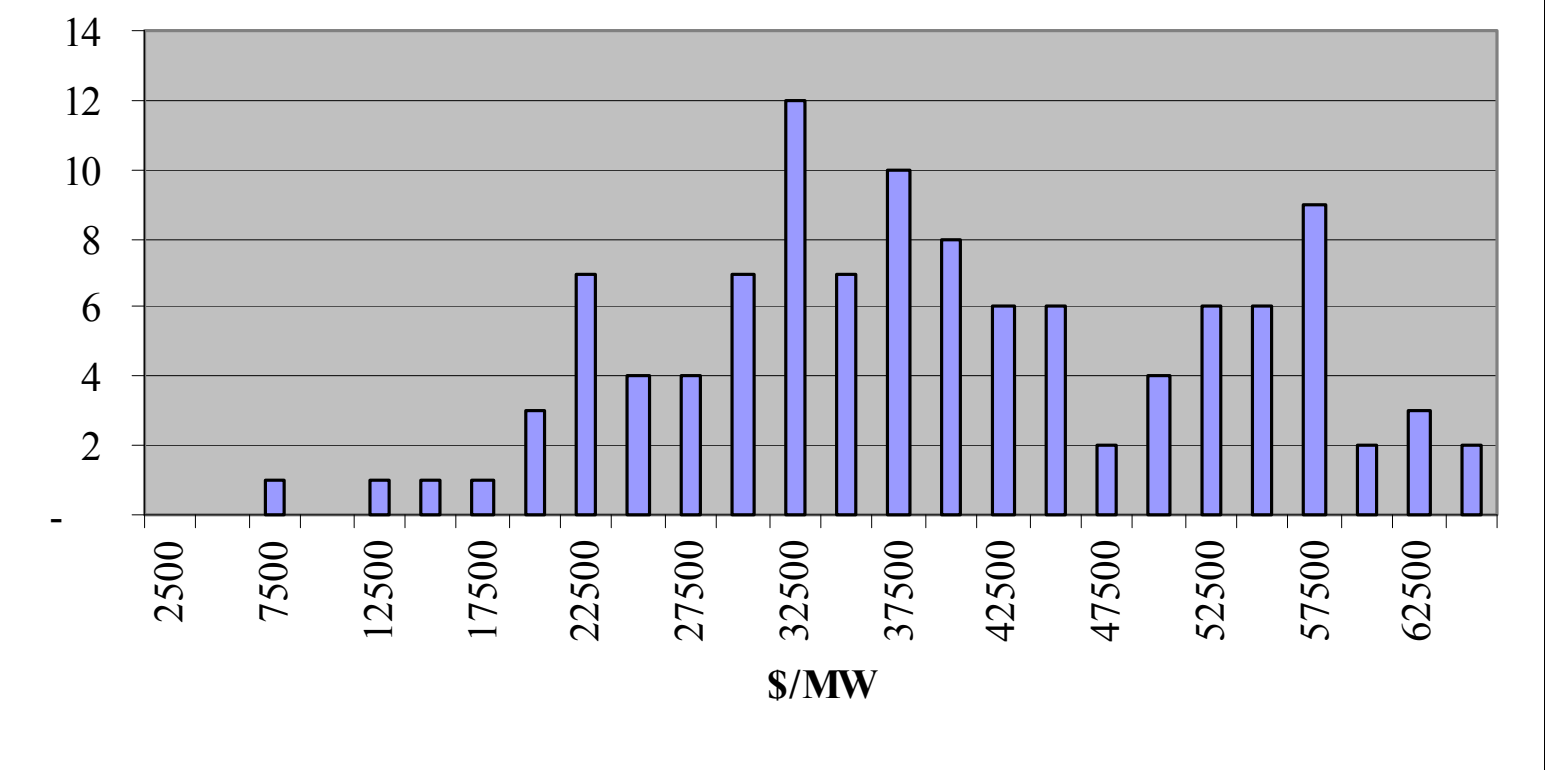




\subsection{Lines and Feeders Embedded Plant Investment}

The five highest cost and five lowest cost utilities for the 5-year average investment in lines and feeders per average MW of system peak are reflected in Table 4.

For lines and feeders, the deviation from the average for the lowest and highest cost utilities is also fairly dramatic, though not as great as the variability for transformers and substations ranging from approximately $1 / 3$ the average for the lowest cost utility to almost three times the average for the highest cost utility. The standard deviation for the group is approximately $\$ 100,000$, meaning that approximately $68 \%$ of the utilities are in the range from about $60 \%$ of the average to 1.4 times the average. Again, this is a relatively large spread, indicating the need to consider individual utility circumstances carefully.

Table 4

Average Lines and Feeders Plant Investment Per Average System Peak (1995-1999)

\begin{tabular}{|r|r|r|}
\hline \multicolumn{1}{|c|}{ Company } & $\begin{array}{c}\text { Lines and Feeders Plant } \\
\text { Investment Per System Peak }\end{array}$ \\
\hline 1 & New Hampshire Electric Cooperative, Inc. & $\$ 732,359$ \\
\hline 2 & Consolidated Edison Company of New York, Inc. & $\$ 561,676$ \\
\hline 3 & San Diego Gas and Electric Company & $\$ 473,140$ \\
\hline 4 & Commonwealth Electric Company & $\$ 443,330$ \\
\hline 5 & BANGOR HYDRO-ELECTRIC COMPANY & $\$ 440,338$ \\
\hline & Average & $\$ 237,644$ \\
\hline 120 & Ohio Power Company & $\$ 108,150$ \\
\hline 121 & Lockhart Power Company & $\$ 102,673$ \\
\hline 122 & Southwestern Public Service Company & $\$ 91,505$ \\
\hline 123 & Northwestern Public Service & $\$ 88,950$ \\
\hline 124 & Northern States Power Company (Wisconsin) & $\$ 79,787$ \\
\hline Statistical Summary & $\$ 100,906$ \\
\hline Standard Deviation & $\$ 237,644$ \\
\hline Average & 0.89 \\
\hline Correlation & $\$ 136,738$ \\
\hline Average Plus Standard Deviation & \multicolumn{1}{|c|}{ Average Less Standard Deviation } & \\
\hline
\end{tabular}


Chart 5 shows the distribution of lines and feeders plant investment per MW with the data grouped in $\$ 25,000$ increments. In this case 105 of the 124 companies have investments per MW between $\$ 125,000$ and $\$ 375,000$. Like transformers and substations, the lines and feeders plant show a wide range of experience. Lines and feeders plant investments appear too more closely approximate a Gaussian (bell-shaped), distribution among the utilities, although the data exhibits an extended high cost tail.

\section{Chart 5}

\section{Distribution of Lines \& Feeders Investment Per MW of System Peak}

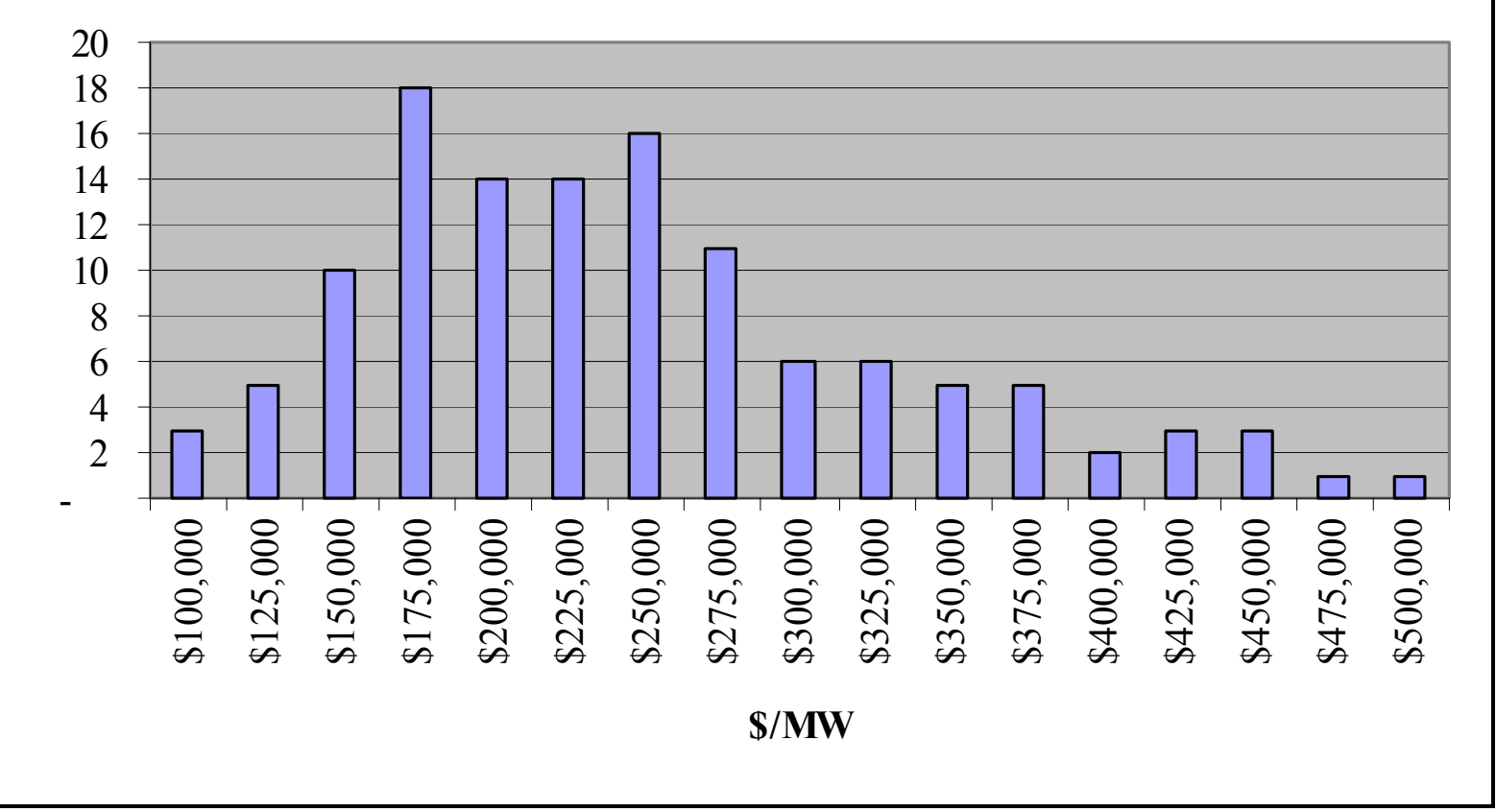




\section{Embedded O\&M Expenses}

\subsection{Transformer and Substation Embedded O\&M Expense}

In addition to investments in plant in service, we analyzed the associated O\&M costs for the two categories of distribution plant. Table 5 shows the 5-year average transformer and substation O\&M expenses per average system peak for the five highest cost and five lowest cost utilities.

Table 5

\begin{tabular}{|c|c|c|}
\hline \multicolumn{3}{|c|}{$\begin{array}{c}\text { Average Transformers and Substations O\&M Expense Per Average System Peak } \\
(1995-1999)\end{array}$} \\
\hline Rank & Company & $\begin{array}{c}\text { Transformers } \\
\text { and } \\
\text { Substations } \\
\text { O\&M Expense } \\
\text { Per System } \\
\text { Peak }\end{array}$ \\
\hline & Central Vermont Public Service Corporation & $\$ 1,570$ \\
\hline 2 & Connecticut Valley Electric Company Inc. & $\$ 1,455$ \\
\hline 3 & Alaska Electric Light and Power Company & $\$ 1,426$ \\
\hline 4 & The United Illuminating Company & $\$ 1,337$ \\
\hline 5 & Upper Peninsula Power Company & $\$ 1,200$ \\
\hline & Average & $\$ 424$ \\
\hline 120 & Indianapolis Power and Light Company & $\$ 59$ \\
\hline 121 & South Carolina Electric and Gas Company & $\$ 50$ \\
\hline 122 & Potomac Electric Power Company & $\$ 38$ \\
\hline 123 & CITIZENS' ELECTRIC COMPANY & $\$ 0$ \\
\hline 124 & South Beloit Water, Gas and Electric Company & $\$ 0$ \\
\hline \multicolumn{3}{|c|}{ Statistical Summary } \\
\hline & Standard Deviation & $\$ 306$ \\
\hline & Average & $\$ 424$ \\
\hline & Correlation & 0.71 \\
\hline & Average Plus Standard Deviation & $\$ 730$ \\
\hline & Average Less Standard Deviation & $\$ 118$ \\
\hline
\end{tabular}

Like plant in service amounts, the O\&M data show a high degree of variability. The standard deviation for transformers and substations O\&M expense for the 124 companies is approximately $\$ 306$. This is approximately seventy percent the average itself, which equates to a range for the standard deviation from $\$ 118$ to $\$ 730$, a seven-fold difference. 
Chart 6 shows the distribution of Lines and Feeders O\&M Expenses per MW of system peak in increments of $\$ 1,000$. All but eleven of the companies fall within the range of $\$ 2,000$ to $\$ 15,000$. Ninety-two of the companies, or approximately $74 \%$, have costs between $\$ 2,000$ and $\$ 9,000$.

Chart 6

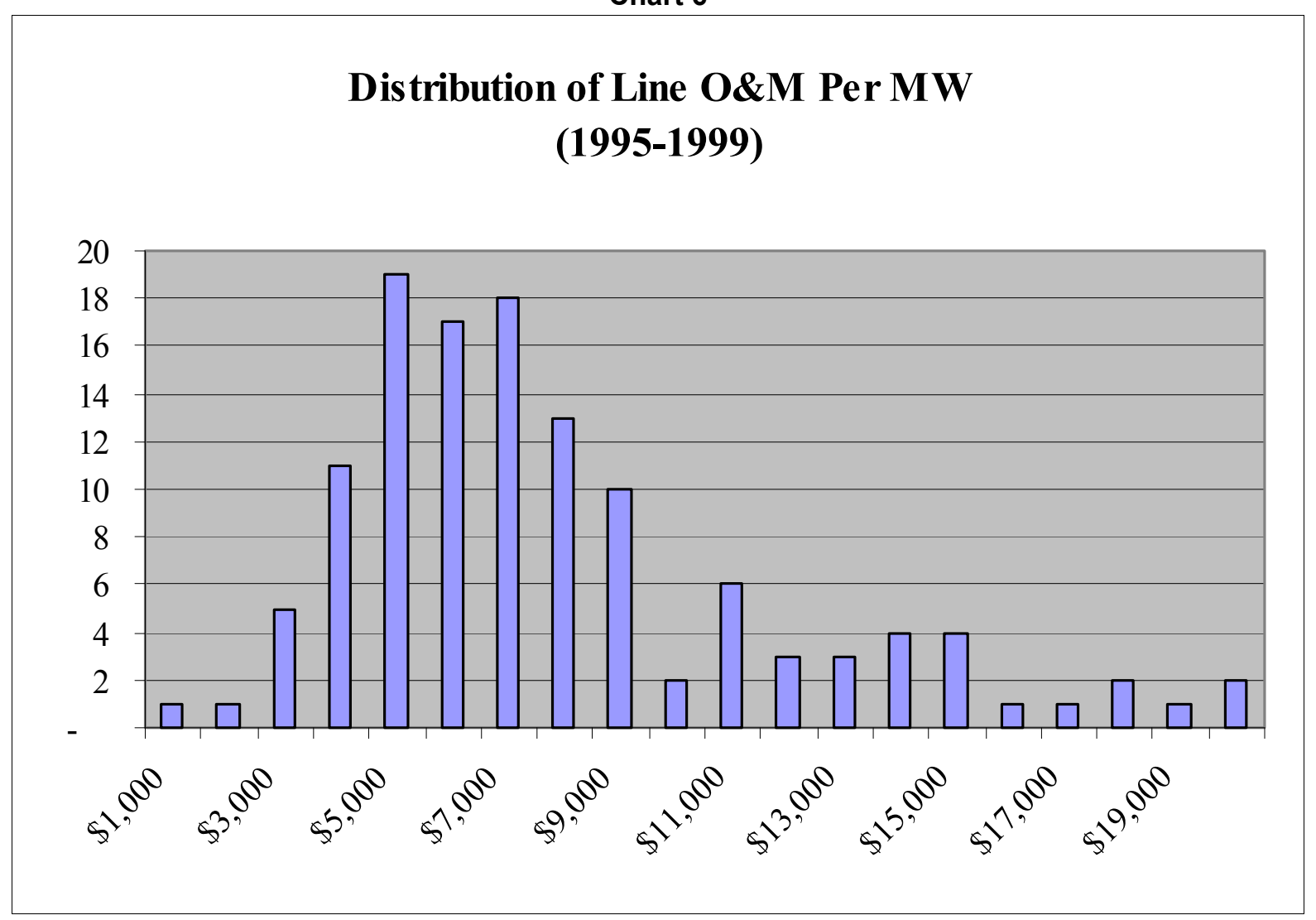


Table 6 reflects embedded O\&M costs per MW for transformers and substations for the five highest cost and the five lowest cost utilities.

Again, the data show a high degree of variability. The standard deviation for lines and feeders O\&M expense for the 124 companies is $\$ 4,470$. The range of the standard deviation is from $\$ 3,201$ to $\$ 12,141$.

Table 6

Average Lines and Feeders O\&M Expense per Average System Peak (1995-1999)

\begin{tabular}{|r|l|r|}
\hline Rank & \multicolumn{1}{|c|}{ Company } & $\begin{array}{r}\text { Lines and } \\
\text { Feeders O\&M } \\
\text { Expense Per } \\
\text { System Peak }\end{array}$ \\
\hline 1 & Central Vermont Public Service Corporation & $\$ 26,649$ \\
\hline 2 & New Hampshire Electric Cooperative, Inc. & $\$ 25,430$ \\
\hline 3 & Connecticut Valley Electric Company Inc. & $\$ 19,610$ \\
\hline 4 & Upper Peninsula Power Company & $\$ 18,626$ \\
\hline 5 & Newport Electric Corporation & $\$ 17,258$ \\
\hline & Average & $\$ 7,671$ \\
\hline 120 & Lockhart Power Company & $\$ 2,692$ \\
\hline 121 & Tucson Electric Power Company & $\$ 2,631$ \\
\hline 122 & Central Power and Light Company & $\$ 2,586$ \\
\hline 123 & Southwestern Public Service Company & $\$ 1,676$ \\
\hline 124 & South Beloit Water, Gas and Electric Company & $\$ 89$ \\
\hline \multicolumn{2}{|l|}{ Statistical Summary } & $\$ 4,470$ \\
\hline \multicolumn{2}{|l|}{ Standard Deviation } & $\$ 7,671$ \\
\hline \multicolumn{2}{|l|}{ Average } & 0.83 \\
\hline \multicolumn{2}{|l|}{ Correlation } & $\$ 12,141$ \\
\hline \multicolumn{2}{|l|}{ Average Plus Standard Deviation } \\
\hline Average Less Standard Deviation
\end{tabular}


Chart 7 shows the distribution of transformers and substations O\&M expense per MW of system peak in $\$ 50$ increments. Unlike the other categories, transformer and substation O\&M expense is widely dispersed from under $\$ 50$ to over $\$ 1,000$. While there is some clustering of the data in the $\$ 150$ to $\$ 450$ range, there are significant numbers of companies with costs all along the spectrum.

\section{Chart 7}

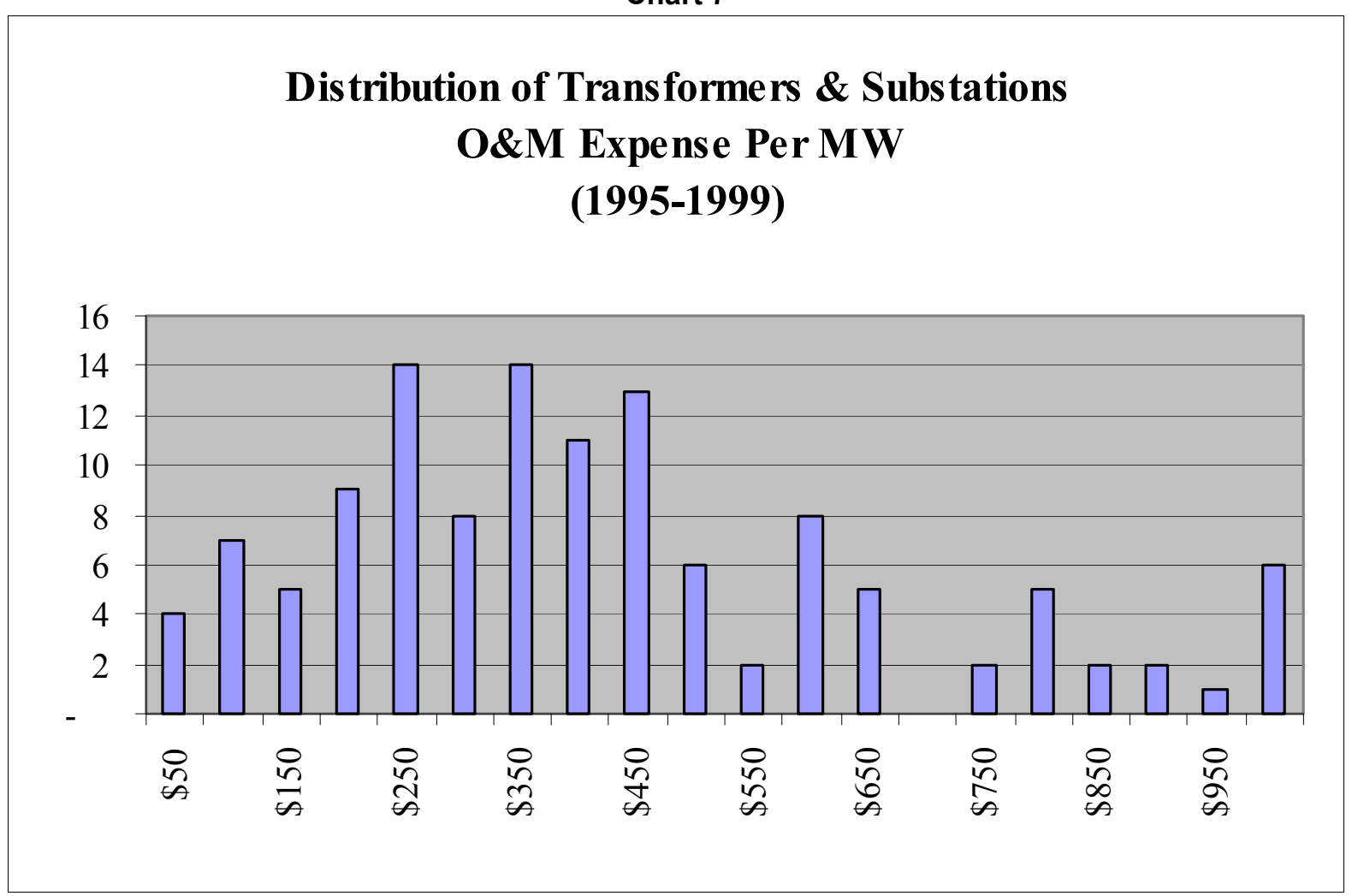

\subsection{Summary of Embedded Costs}

One general conclusion that can be drawn from the data is that the embedded costs of the distribution system are much more heavily weighted toward lines and feeders than transformers and substations - the former being roughly six times higher than the latter on a per MW peak basis. This is significant for two reasons. First, the much higher cost per MW increases the likelihood that any given DR option may be a preferred alternative to a line and feeder system upgrade. Second, lines and feeders carry lower loads on an individual basis than do transformers and substations and so may be more suitable to alternatives involving smaller DR options. On the other hand, DR alternatives for lines and feeders will generally 
involve placement at or near the loads themselves, while DR alternatives to transformers and substation improvements generally involve placement of DR at the substation itself, which is generally simpler. Many DR alternatives, such as load management and energy efficiency options, are at the site of the load anyway, suggesting that they would be a good fit for consideration as alternatives to lines and feeders improvements.

More importantly, for the most expensive of these utilities, average cost per MW for lines and feeders is as high as the current installed cost of many DR options, including wind and microturbines, strongly suggesting that DR options would have competed well historically, had these technologies been available. Indeed, because all these data represent average costs, there are likely many parts of the systems of these utilities that have even higher costs per MW. 


\section{Marginal Costs}

Embedded costs are only the beginning of understanding distribution costs on a goingforward basis. Of much more importance are the marginal costs incurred by utilities as they expand and improve their existing systems. To assess the magnitude of marginal costs for transformers and substations and lines and feeders, we applied the same cost classifications outlined above to the additions to plant in service and to the annual changes in O\&M expenses. One complication present in the marginal cost analysis not present in the embedded cost analysis is that 11 of the utilities experienced negative load growth during the analysis period. It should be noted that these negative growth utilities nonetheless had over $\$ 46$ million of new investment in lines and feeders and transformers and substations, demonstrating the fact that any utility can still face growth constraints and other investment demands within its system, even when the overall company demand is not growing. We have ignored the negative growth companies in order to avoid the difficulties they present in analysis.

We also found that two companies, Central Vermont Public Service Corporation and The Potomac Edison Company, exhibited lines and feeder costs roughly four to nine times higher, respectively, than the next highest cost utilities. In the case of transformers and substations, three companies, Potomac Edison, Central Vermont PSC, and New Hampshire Electric Cooperative exhibited costs that were clearly out of line with the rest of the companies in the data set, ranging from roughly approximately 2.3 to almost seven times the cost of the next highest company. Accordingly, we have adjusted the standard deviation calculations for marginal costs to exclude the negative growth companies and the highest outliers for purposes of the presentations here. 


\section{The Relation of Growth in Investment to Growth in Company Size}

\subsection{Growth in}

Transformer and Substation Plant Investment

As for embedded investments where we compared investments to system peak, system energy, and number of customers, we tested the marginal investment data for correlation to growth in system peak, growth in system sales, and growth in number of customers.

Chart 8 shows the relationship between growth in transformers and substations and growth in system peak, along with a linear trendline. For transformers and substations, the data have an adjusted $\mathrm{R}^{2}$ of .75 for growth in system peak, .75 for customer growth and .37 for growth in system energy. The values indicate a slightly lower correlation between plant investment and both system peak and sales, as compared to embedded costs. Growth in investment has little, if any, relationship to energy consumption. However, peak demand shows a strong relationship to growth in investment and growth in numbers of customers.

\subsection{Growth in Lines and Feeders Investment}

Similar results were found for lines and feeders, where the $\mathrm{R}^{2}$ for system peak is 0.80 on a peak growth basis, 0.82 on a customer growth basis, and 0.41 on a sales growth basis. It is not immediately clear from the data why the $\mathrm{R}^{2}$ for system peak growth is stronger for lines and feeders than it is for transformers and substations. We suspect that this is at least partially caused by the fact that lines and feeders carry smaller units of demand and are installed or expanded in smaller units than transformers and substations - therefore more closely tracking incremental growth on the system. In addition, a review of the distribution projects proposed in 1999 for Commonwealth Edison of Chicago revealed a large number of projects that involved reallocating lines and feeder loads from one transformer or substation to another. In these cases, the bulk of the expenses and investments appear to be allocated to lines and feeders. 


\section{Relationship of Growth in Investment to System Growth Rates}

We also tested the growth in investment against growth rates in system size. That is, are the growth in investments per MW or megawatt-hour (MWH) of growth in system peak or system sales ( $\Delta$ Plant in Service $/ \Delta \mathrm{MW}$ or $\Delta$ Plant in Service/ $\Delta \mathrm{MWH}$ ) higher or lower for companies that are growing more quickly? As was the case for plant investment levels, there is no correlation between growth in investment per MW of system peak with the growth rate of the system.

\section{Chart 9}

\section{Growth in Lines \& Feeders Plant Per Growth in System Peak vs.} Growth in System Peak (5 Yr. Adjusted Average 1995-1999)

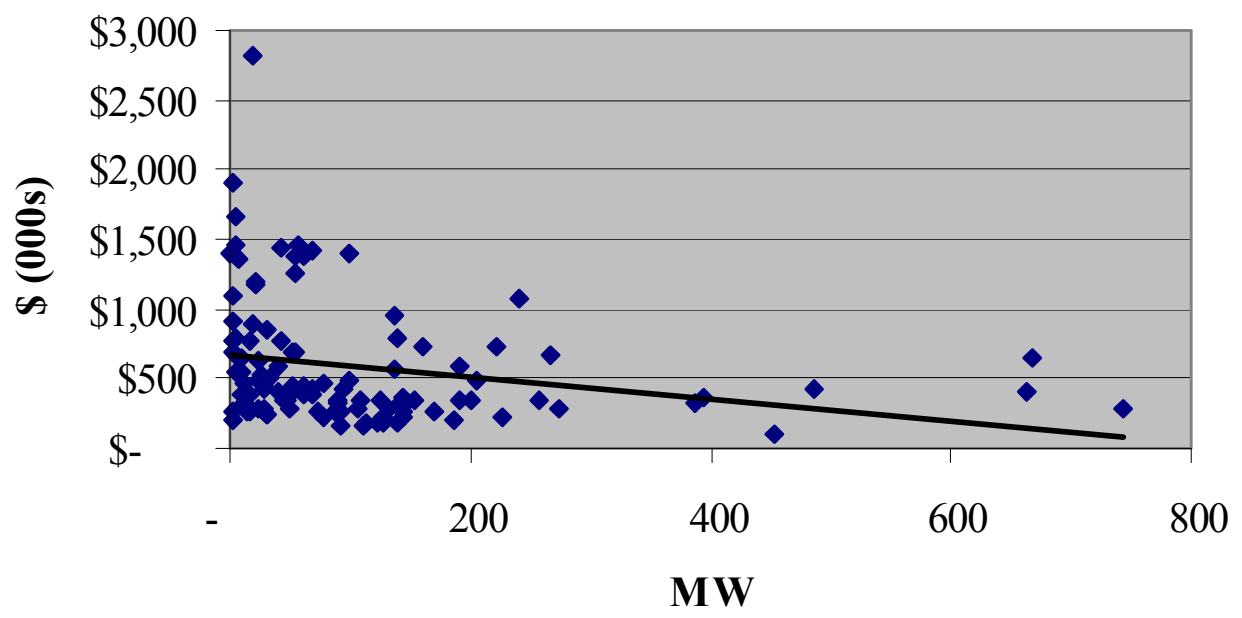

Data in Chart 9 reflect growth in lines and feeders investment per MW of growth in system peak compared to growth in total peak size. Similar to the results for embedded costs, the data have an $\mathrm{R}^{2}$ of -0.04 . A comparable analysis on the basis of growth in total sales volume shows an $\mathrm{R}^{2}$ of -0.06 when compared to system peak and system sales, respectively. For Transformers and Substations the $\mathrm{R}^{2}$ values are -0.05 for system peak and -0.22 system sales. In other words, rapid growth does not translate into a higher cost per MW on an incremental basis. 


\subsection{Marginal Cost of Transformers and Substations Plant}

Table 7 shows the marginal investment in lines and feeders per MW of system peak growth for the seven highest and five lowest cost utilities, excluding utilities with negative system peak growth.

Table 7

Average Growth In Lines and Feeders Investment per MW of System Peak Growth
$(\mathbf{1 9 9 5 - 1 9 9 9 ) *}$


The adjusted data exhibit a standard deviation of $\$ 91,062$ against an average of $\$ 98,549$. Again, this indicates a very high spread in the values.

Chart 10 reflects the distribution of growth in transformer and substation plant investment per MW of growth in system peak in $\$ 10,000$ increments. Eighty of the companies have growth in investment between $\$ 30,000$ and $\$ 130,000$ per MW of growth, an extremely wide range. Thirteen companies are reflected as less than zero because of their negative load growth during the analysis period. Another 20 companies are spread fairly evenly out to $\$ 380,000$. Of the three remaining companies, two are definite outliers with costs of $\$ 1.2$ million and \$3.6 million per MW.

Chart 10

\section{Distribution of Growth in Transformers \& Substation Plant Investment Per M W Growth in System Peak (1995-1999)}

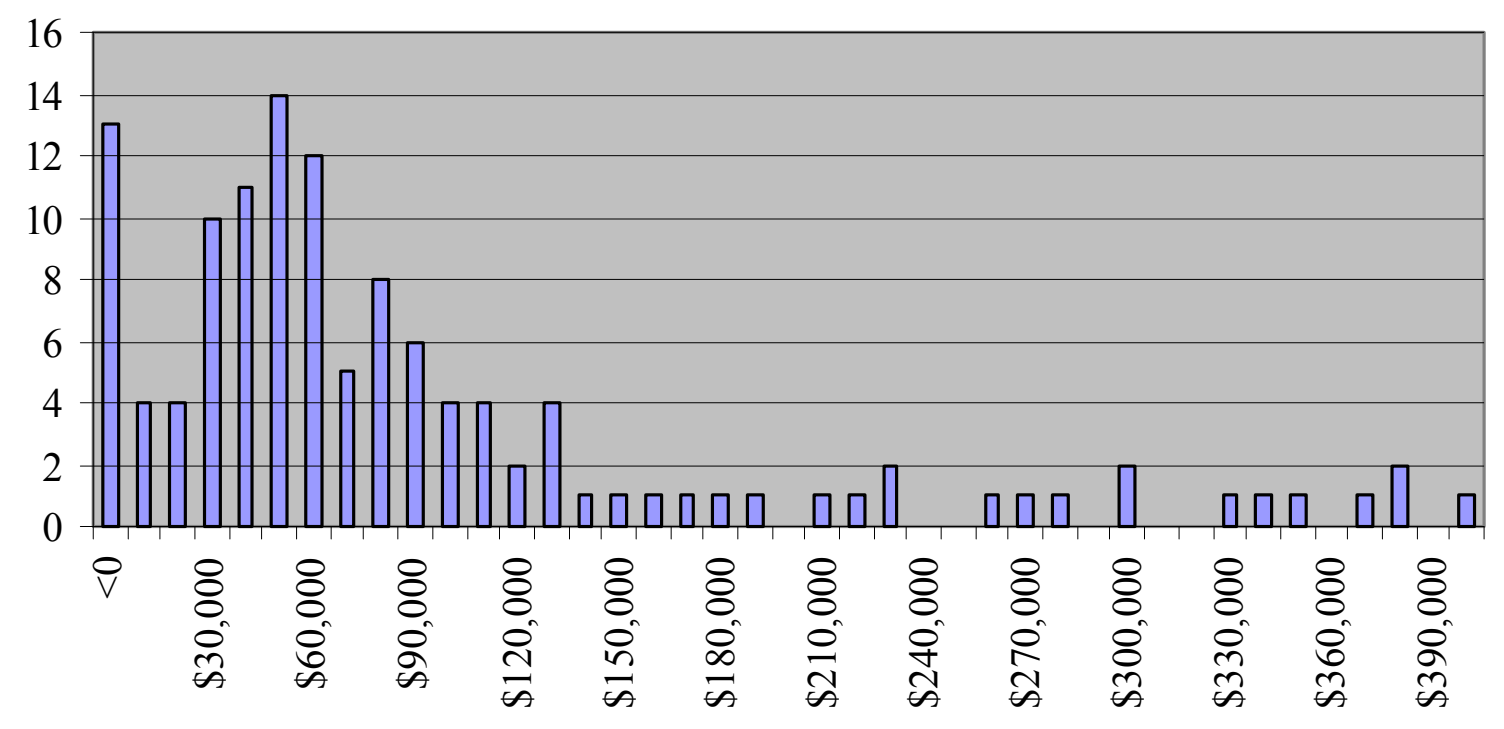

\subsection{Marginal Lines and Feeders Plant Investment}

Table 8 reflects the 5-year average growth in lines and feeders plant investment per MW of growth in system peak.

Data for lines and feeders marginal costs for companies with positive growth in system peak have a standard deviation of more than $\$ 2.7$ million per MW on an unadjusted basis. 
However, excluding the three highest outliers lowers the standard deviation significantly to approximately $\$ 447,964$, approximately $75 \%$ of the adjusted average of $\$ 589,524$. This still indicates a very wide spread of values for the data.

Table 8

\section{Growth in Lines and Feeder Plant Investment Per MW Growth in System \\ Peak}

$(1995-1999)^{*}$

\begin{tabular}{|c|c|c|}
\hline Rank & Company & $\begin{array}{l}\text { Growth in } \\
\text { Lines and } \\
\text { Feeders Plant } \\
\text { Investment Per } \\
\text { Growth in } \\
\text { System Peak }\end{array}$ \\
\hline 1 & THE POTOMAC EDISON COMPANY & $\$ 19,483,006$ \\
\hline 2 & New Hampshire Electric Cooperative, Inc. & $\$ 7,130,319$ \\
\hline 3 & Central Vermont Public Service Corporation & $\$ 6,474,471$ \\
\hline 4 & Pennsylvania Electric Company & $\$ 2,815,919$ \\
\hline 5 & Upper Peninsula Power Company & $\$ 1,902,999$ \\
\hline & Average & $\$ 608,215$ \\
\hline 107 & Western Resources, Inc. & $\$ 184,459$ \\
\hline 108 & Entergy Mississippi, Inc. & $\$ 174,603$ \\
\hline 109 & Toledo Edison Company, The & $\$ 163,059$ \\
\hline 110 & Kansas Gas and Electric Company & $\$ 155,231$ \\
\hline 111 & Entergy Arkansas, Inc. & $\$ 108,886$ \\
\hline \multicolumn{3}{|c|}{ Statistical Summary† } \\
\hline & Standard Deviation & $\$ 447,964$ \\
\hline & Average & $\$ 589,524$ \\
\hline & Correlation & 0.83 \\
\hline & Average Plus Standard Deviation & $\$ 1,037,488$ \\
\hline & Average Less Standard Deviation & $\$ 141,559$ \\
\hline
\end{tabular}

*Excludes negative growth companies

${ }^{\dagger}$ Excludes negative growth companies and three highest outliers 
As shown in Chart 11, there is considerable clustering of the data in the $\$ 100,000$ per MW to $\$ 800,000$ per MW range, with 24 of the companies lying above this range. Thirteen of the companies show negative values, reflecting their negative growth over the study period.

Chart 11

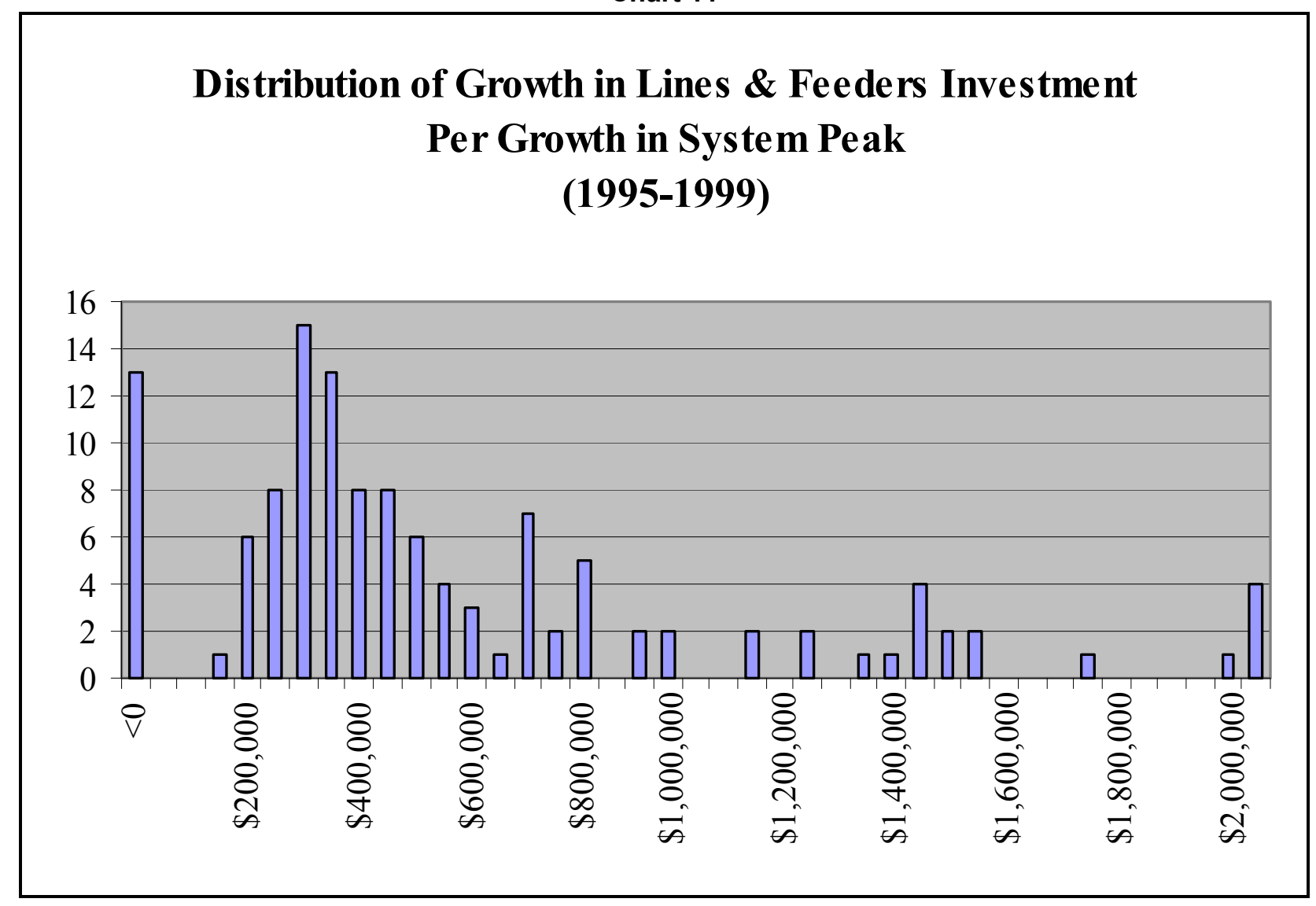

\subsection{Marginal O\&M Costs}

We reviewed the data for marginal O\&M costs using the same methods applied to marginal investments in plant-in-service. These data exhibit extreme variability, including large negative values. This appears to be the result of cost reduction programs and the periodicity of O\&M activities. In addition, there is no clear basis from the FERC Form 1 format to tie marginal O\&M expenses to marginal plant investments. As a result, we have not used the marginal O\&M expenses as part of our analysis. Instead, we have used the embedded O\&M cost information previously discussed. Likely, this understates these costs slightly. 


\section{General Discussion of Marginal Cost Data}

As would be expected, the marginal costs for most utilities (109 of 124) exceeded their embedded costs. Chart 12 reflects the percentage by which lines and feeders marginal plant investment per MW

exceeds embedded investment per MW for all of the companies in the study.

The distribution of the percentage by which lines and feeders marginal investment per MW growth in system peak exceeds embedded investment per MW of system peak is grouped in 25\% increments, reflected in Chart 12. Nineteen of the utilities experienced marginal investment rates that are less than their embedded investment rates or exhibited negative growth. Of the remaining 106 utilities, 74 have marginal costs that exceed their embedded costs

by $100 \%$ or more. The excess of marginal investment per marginal MW over embedded investment per embedded

MW is a significant source of risk for escalating distribution costs and higher rates, looking forward.

Recent experience in California, Chicago, and other urban areas suggest there is increasing pressure on the distribution infrastructure, especially during peak summer periods. Continued
Chart 12

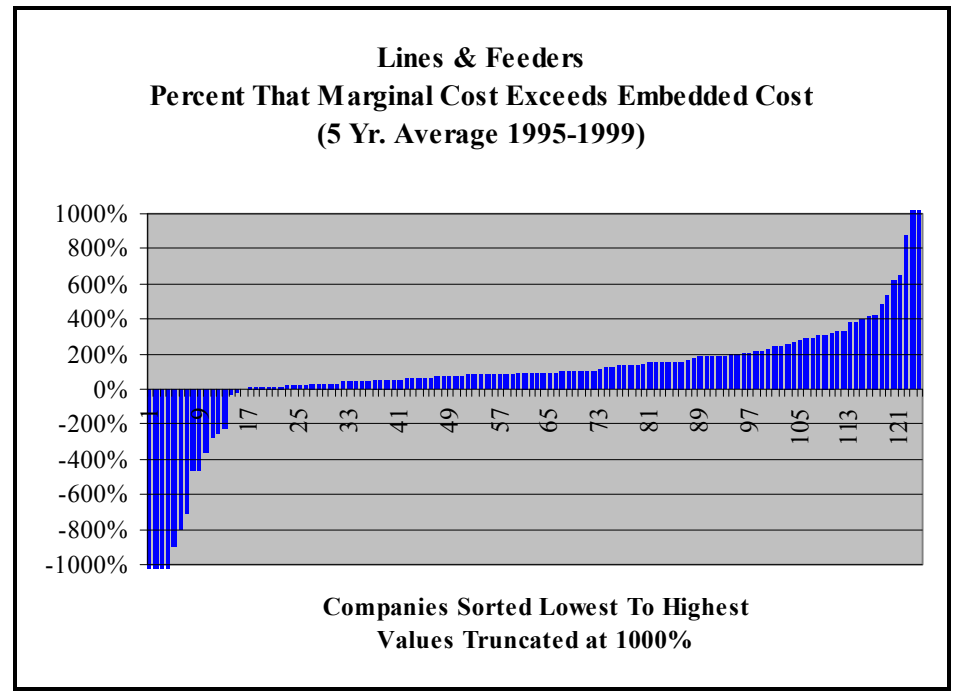

Chart 13

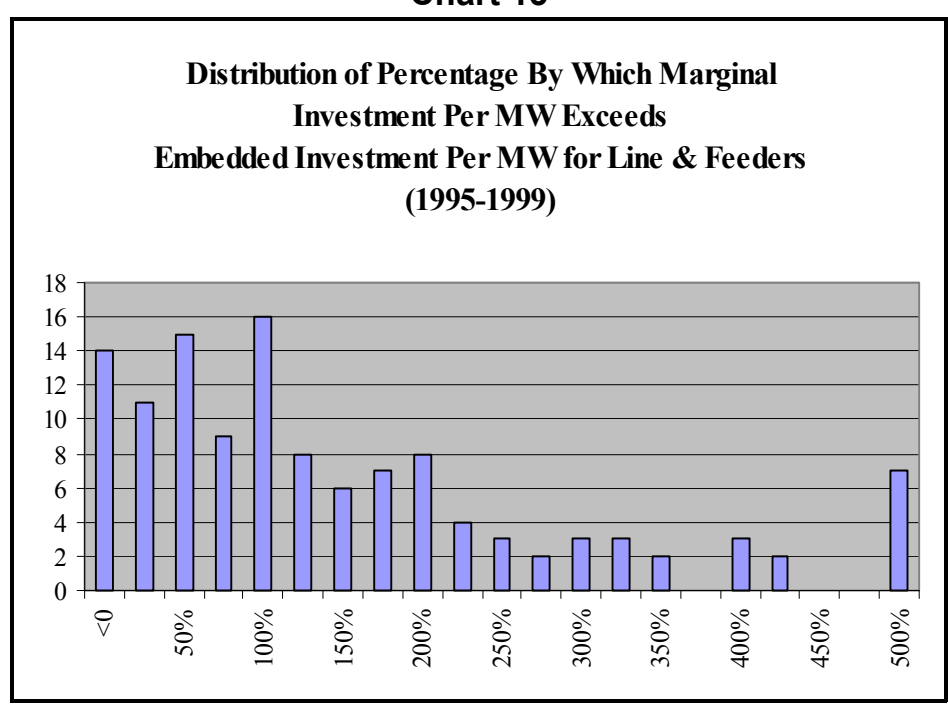

growth will only stress the system further, requiring further investment in the distribution system to alleviate these problems. During the analysis period used here, 1995-1999, the 124 utilities reviewed invested more than $\$ 32$ billion in the combined lines and feeders and transformers and substations categories. As this number increases over time, the differential between marginal cost and embedded cost is only likely to widen. The impact on the customer would be ever-increasing costs. Luckily, the very parts of the system that are under stress represent the target opportunities for DR and other DR solutions. System expansions involving brand new construction or new 
housing subdivisions, for example, cannot generally be deferred with DR solutions. Transformers and substations and lines and feeders that are at, or nearing, their capacity do represent such opportunities. The value of DR in this context can be very high.

The data we have reviewed here exhibit high variability from utility to utility. It should be pointed out that these data are averages for each utility, both in terms of years and, more importantly, of all projects for each year for each utility. Within each utility, there are literally dozens of projects per year involving a wide range of different expenditures. If each utility experiences the kind of variability in costs from project to project as we have seen from utility to utility, it suggests that many projects may have extremely low costs per MW, while others have extremely large costs per MW. Examination of individual utility data confirms that this is exactly the case.

\subsection{Commonwealth Edison Data for 1999}

A review of construction project data obtained from Commonwealth Edison shows high variability in the cost of 963 lines and feeders projects considered in 1999. For Commonwealth Edison, project specific costs exhibited a standard deviation equal to $94 \%$ of their average, a value comparable to that shown among the 124 companies in the data set as a whole. This demonstrates the wide variability that any single company might see in the costs on its system.

To derive a sense of how cost within any given utility might vary, we used the standard deviation of the Commonwealth Edison data set to define potential "High" and "Low" cases for all of the companies in the study. For lines and feeders using Commonwealth Edison's standard deviation to establish a range yields a high case equal to $194 \%$ of the average and a low case equal to $6 \%$ of the average. Similarly, for the 214 transformer and substation projects, the data showed a standard deviation equal to $76 \%$ of the average, yielding a range from $176 \%$ of average down to $24 \%$ of average.

We used these ranges to bound the upper and lower costs for each category for selected utilities and then computed a levelized cost per megawatt for each category. For this calculation we assumed a 30-year investment life, a 10\% weighted cost of capital, a 10\% discount rate, and a 3\% O\&M escalation rate. With this information, a revenue requirement stream is calculated and present values for each year are derived. Finally, a deferral value was calculated, simply the sum of the present values for each year for the number of years in question. Using this method, we derived the value of deferring projects for a number of years ranging from 1 to 30 . This method allows us to bracket the potential costs for any of the utilities within our data set.

For example, Table 9 is a summary of low and high case values for Central Vermont Public Service Corporation, one of the higher cost utilities. For example, in the lines and feeders "high" case, if a lines and feeders project could be deferred for 5 years, the utility would be better off installing any DR options that have a cost of $\$ 6,273$ per kilowatt $(\mathrm{kW})$ or less. The longer an upgrade can be deferred, the greater the value of the DR alternative. Not surprisingly, this analysis suggests that Central Vermont may have significant opportunities for incorporating DR cost effectively. 
Table 9

\section{Value of Project Deferring DR $(\$ / k W)$}

\begin{tabular}{|c|c|c|c|c|}
\hline \multirow{3}{*}{$\frac{\text { Companv }}{\text { Marginal }}$} & \multicolumn{4}{|c|}{ Central Vermont Public Service Corporation } \\
\hline & \multicolumn{2}{|c|}{$\begin{array}{c}\text { Transformers and } \\
\text { Substations }\end{array}$} & \multicolumn{2}{|c|}{ Lines and Feeders } \\
\hline & $\$ 302.586$ & $\$ 2.229 .074$ & $\$ 407.747$ & $\$ 12.541 .195$ \\
\hline \multirow[t]{2}{*}{ Deferral Years } & \multicolumn{2}{|c|}{ Case } & \multicolumn{2}{|c|}{ Case } \\
\hline & Low & High & Low & High \\
\hline 1$]$ & $\$ 37$ & $\$ 270$ & $\$ 49$ & $\$ 1,520$ \\
\hline 2 & $\$ 71$ & $\$ 521$ & $\$ 95$ & $\$ 2,933$ \\
\hline 3. & $\$ 101$ & $\$ 744$ & $\$ 136$ & $\$ 4,185$ \\
\hline 4 & $\$ 128$ & $\$ 941$ & $\$ 172$ & $\$ 5,293$ \\
\hline 5 & $\$ 151$ & $\$ 1,115$ & $\$ 204$ & $\$ 6,273$ \\
\hline 6. & $\$ 172$ & $\$ 1,269$ & $\$ 232$ & $\$ 7,140$ \\
\hline ... & $\$ 191$ & $\$ 1,405$ & $\$ 257$ & $\$ 7,905$ \\
\hline 8 & $\$ 207$ & $\$ 1,525$ & $\$ 279$ & $\$ 8,580$ \\
\hline 9. & $\$ 221 !$ & $\$ 1,631$ & $\$ 299$ & $\$ 9,175$ \\
\hline 10 & $\$ 234$ & $\$ 1,724$ & $\$ 316$ & $\$ 9,699$ \\
\hline 11 & $\$ 245$ & $\$ 1,806$ & $\$ 331$ & $\$ 10,160$ \\
\hline 12 & $\$ 255$ & $\$ 1,878$ & $\$ 344$ & $\$ 10,565$ \\
\hline 13 & $\$ 264$ & $\$ 1,941$ & $\$ 356$ & $\$ 10,921$ \\
\hline 14 & $\$ 271$ & $\$ 1,996$ & $\$ 366$ & $\$ 11,232$ \\
\hline 15 & $\$ 278$ & $\$ 2,045$ & $\$ 375$ & $\$ 11,505$ \\
\hline 16 & $\$ 283$ & $\$ 2,087$ & $\$ 382$ & $\$ 11,744$ \\
\hline 17 & $\$ 288$ & $\$ 2,124$ & $\$ 389$ & $\$ 11,952$ \\
\hline 18 & $\$ 293$ & $\$ 2,157$ & $\$ 395$ & $\$ 12,133$ \\
\hline 19 & $\$ 297$ & $\$ 2,185$ & $\$ 400$ & $\$ 12,291$ \\
\hline 20 & $\$ 300$ & $\$ 2,209$ & $\$ 405$ & $\$ 12,428$ \\
\hline 21 & $\$ 303$ & $\$ 2,230$ & $\$ 409$ & $\$ 12,54$ \\
\hline 22 & $\$ 305$ & $\$ 2,248$ & $\$ 412$ & $\$ 12,649$ \\
\hline 23 & $\$ 307$ & $\$ 2,264$ & $\$ 415$ & $\$ 12,737$ \\
\hline 24 & $\$ 309$ & $\$ 2,277$ & $\$ 417$ & $\$ 12,813$ \\
\hline 25 & $\$ 311$ & $\$ 2,229$ & $\$ 419$ & $\$ 12,878$ \\
\hline 26 & $\$ 312$ & $\$ 2,299$ & $\$ 421$ & $\$ 12,933$ \\
\hline 27. & $\$ 313$ & $\$ 2,307$ & $\$ 423$ & $\$ 12,980$ \\
\hline 28 & $\$ 314$ & $\$ 2,314$ & $\$ 424$ & $\$ 13,019$ \\
\hline 29 & $\$ 315$ & $\$ 2,320$ & $\$ 425$ & $\$ 13,052$ \\
\hline 30 & $\$ 316$ & $\$ 2,325$ & $\$ 426$ & $\$ 13,080$ \\
\hline
\end{tabular}


The values reflected here represent the maximum amount the utility should be willing to pay, on a per-kW basis, to invest in a DR alternative to a given "wires and transformers" project and should be considered as a tool to help the policy maker understand the order of magnitude of these costs. Individual projects may exhibit values that exceed those shown here, depending upon the circumstances.

Because of the high variation from average cost that each utility might see on its own system, it is not just the high-cost utilities that might effectively use DR. Table 10 reflects the high and low case values for Southwestern Electric Power Company, a generally low cost utility. While very short term deferrals would be unlikely to generate enough savings to justify DR, longer term projects might very well generate enough savings to make DR the economic choice, as compared to a "wires and transformers" alternative.

These values show that DR alternatives have significant values even for "low cost" utilities, at least for longer period deferrals. In addition, it should be noted that these values represent capacity values only. Economic dispatch of DR would likely yield additional energy value to the utility or customer, especially where costs are tied to short-term or spot markets. The energy values have not been analyzed in this paper because they are outside the scope of our review.

\subsubsection{Timing Is as Important as Geography}

The cost effectiveness of DR options is affected by the timing of system improvements, as well as the geography. The highest value DR occurs on systems where the total load is at or near the capacity of the substation or feeder and the growth on that system is slow. This combination means that a DR investment has can defer "wires and transformers" for a much longer period. In cases where the subject portion of the distribution system is not at or near capacity, there is no deferral value associated with a DR investment. In cases where the growth on that part of the system is very high, "wires and transformers" solutions may be inevitable in a short period of time.

However, this does not mean that DR should be purchased only where specific projects will be deferred for long periods of time. First, it should be noted that the costs identified in this paper represent only distribution deferral costs. DR investments may have other values as well, including energy cost savings, reliability, and other system enhancement value.

More importantly, some DR is by its very nature a portable installation. This may be especially true for the microturbine and fuel cell technologies. As a result, these technologies can effectively capture the maximum life values - 30 years in our example tables - if they are relocated on the system on an as-needed basis. In this scenario, a turbine might delay the upgrade of a feeder for 3 years, then be moved to a substation where it can defer upgrades for 2 years, then be relocated to defer another feeder upgrade, and so on. For such portable technologies, almost every utility would have a niche of installations that would justify their purchase and continued use. 
Table 10

\begin{tabular}{|c|c|c|c|c|}
\hline \multicolumn{5}{|c|}{ Value of Project Deferring DR $(\mathbf{\$} / \mathbf{k W})$} \\
\hline \multirow{3}{*}{$\begin{array}{c}\text { Companv } \\
\text { Marginal } \\
\text { \$/MW }\end{array}$} & \multicolumn{4}{|c|}{ Southwestern Electric Power Companv } \\
\hline & \multicolumn{2}{|c|}{$\begin{array}{c}\text { Transformers and } \\
\text { Substations }\end{array}$} & \multicolumn{2}{|c|}{ Lines and Feeders } \\
\hline & $\$ 7.621 \vdots$ & $\$ 56,142$ & $\$ 12.914$ & $\$ 397.210$ \\
\hline \multirow[t]{2}{*}{ Deferral Years } & Case & & Case & \\
\hline & Low & High & Low & High \\
\hline 1. & $\$ 1$ & $\$ 7$ & $\$ 2$ & $\$ 48$ \\
\hline 2. & $\$ 2$ & $\$ 13$ & $\$ 3$ & $\$ 93$. \\
\hline 3. & $\$ 3$ & $\$ 19$ & $\$ 4$ & $\$ 133$ \\
\hline 4 & $\$ 3$ & $\$ 24$ & $\$ 5$ & $\$ 168$ \\
\hline 5 & $\$ 4$ & $\$ 28$ & $\$ 6$ & $\$ 199$ \\
\hline 6 & $\$ 4$ & $\$ 32$ & $\$ 7$ & $\$ 226$ \\
\hline 7 & $\$ 5$ & $\$ 35$ & $\$ 8$ & $\$ 250$ \\
\hline 8 & $\$ 5$ & $\$ 38$ & $\$ 9$ & $\$ 272$ \\
\hline 9 & $\$ 6$ & $\$ 41$ & $\$ 9$ & $\$ 291$ \\
\hline 10 & $\$ 6$ & $\$ 43$ & $\$ 10$ & $\$ 307$ \\
\hline 11 & $\$ 6$ & $\$ 45$ & $\$ 10$ & $\$ 322$ \\
\hline 12 & $\$ 6$ & $\$ 47$ & $\$ 11$ & $\$ 335$ \\
\hline 13 & $\$ 7$ & $\$ 49$ & $\$ 11$ & $\$ 346$ \\
\hline 14 & $\$ 7$ & $\$ 50$ & $\$ 12$ & $\$ 356$ \\
\hline 15 & $\$ 7$ & $\$ 52$ & $\$ 12$ & $\$ 364$ \\
\hline 16 & $\$ 7$ & $\$ 53$ & $\$ 12$ & $\$ 372$ \\
\hline 17 & $\$ 7$ & $\$ 54$ & $\$ 12$ & $\$ 379$ \\
\hline 18 & $\$ 7$ & $\$ 54$ & $\$ 13$ & $\$ 384$ \\
\hline 19 & $\$ 7$ & $\$ 55$ & $\$ 13$ & $\$ 389$ \\
\hline 20 & $\$ 8$ & $\$ 56$ & $\$ 13$ & $\$ 394$ \\
\hline 21 & $\$ 8$ & $\$ 56$ & $\$ 13$ & $\$ 397$ \\
\hline 22 & $\$ 8$ & $\$ 57$ & $\$ 13$ & $\$ 401$ \\
\hline 23 & $\$ 8$ & $\$ 57$ & $\$ 13$ & $\$ 403$ \\
\hline 24 & $\$ 8$ & $\$ 57$ & $\$ 13$ & $\$ 406$ \\
\hline 25 & $\$ 8$ & $\$ 58$ & $\$ 13$ & $\$ 408$ \\
\hline 26 & $\$ 8$ & $\$ 58$ & $\$ 13$ & $\$ 410$ \\
\hline 27 & $\$ 8$ & $\$ 58$ & $\$ 13$ & $\$ 411$ \\
\hline 28 & $\$ 8$ & $\$ 58$ & $\$ 13$ & $\$ 412$ \\
\hline 29 & $\$ 8$ & $\$ 58$ & $\$ 13$ & $\$ 413$ \\
\hline 30 & $\$ 8$ & $\$ 59$ & $\$ 13$ & $\$ 414$ \\
\hline
\end{tabular}




\subsubsection{Distribution System Upgrade Strategies}

Utilities use a variety of different strategies for upgrading the distribution system. A review of the options considered by Commonwealth Edison for 75 problem substations on its system in 1999 reveals that about half of the solutions considered involved rerouting power flows to relieve the load on specific transformers. Most of the rest of the options involved installation of larger transformers. A few of the solutions involved the creation of "super feeders" to increase overall capacity on the affected area of the system. In each case, very specific options were considered and their costs were identified. The average increase in capacity for the various options considered was $16 \mathrm{MW}$. This largest project increased capacity by $72 \mathrm{MW}$ and smallest by just $2 \mathrm{MW}$.

Similar options may be available for lines and feeders - for example, splitting lines and feeders between existing substations or transformers, upgrading the conductors (bigger wires), or rerouting feeders to serve different parts of the system.

These case-by-case analyses are the critical points in the process for determining the economic appropriateness of distributed resources. Even so, it is a part of the process that regulators rarely see or understand. Traditionally, these costs have been reviewed by regulators in the aggregate as part of rate cases or financing cases.

To reveal these costs at a level useful for determining the appropriateness of DR, regulators should develop a standardized reporting format that identifies problem areas on the distribution system. The critical information that should be reported includes the type of problem, the potential "wires and transformers" solutions and their costs, the effective life of the "wires and transformers" solutions, expected growth rates on the affected parts of the distribution system, the cost of DR alternatives, levelized costs for both "wires and transformers" and for DR alternatives. Because some DR may be "redispatched" to defer future distribution costs, utilities should be required to report expected distribution investments and costs over a reasonably long period of at least 5 to 10 years. This may reveal opportunities for cost-effective dispatch of DR that would not be evident from a 1- or 2-year analysis. 


\section{Strategies for the Regulator}

Given the high variability of the costs to upgrade the distribution system between and within utilities, regulators should adopt a reporting scheme designed to highlight opportunities for more cost effective choices than the traditional "wires and transformers" options typically considered by utility distribution system planners. Reports should include forecasts of distribution projects over a period of time that is long enough to foresee major additions and upgrades to the systems and to cover the installation lead times for distributed generation and distributed resource options. Ideally, uniform reports across the country should be adopted to enhance the value of this information. An option here would be for the FERC to amend the FERC Form 1 filing requirements to disclose distribution system expansion costs on project, geographic, and engineering bases.

Obviously, cost information about both traditional wires and transformers options as well as the DR options should be included. Use of a levelized per-kW cost methodology, similar to that developed in this paper, should be used to compare the cost of different options.

Finally, some look-back reporting should be required to compare the actual experience to the previously forecast experience. This should greatly assist the regulator in assessing both the experienced economics of these choices as well as the methodologies being used to make those choices. 


\section{Conclusion}

Distribution system costs have not historically received a high level of scrutiny by regulators.

However, there is every reason to believe that the growth in investment in the distribution system is likely to accelerate over the next several years, raising the efficacy of greater regulatory review. Principal causes for the growth in distribution plant investments and costs include the deterioration of embedded facilities that are at or near the end of their useful lives, expansion and upgrade of facilities that operate at or near their capacity, and continued growth, both geographically and in terms of intensity, of consumer demand. Improvements in efficiency are unlikely to counterbalance this growth.

While generating costs may experience a decline through technological gains in efficiency, costs of the distribution system have no comparable innovations in the wings. The 124 utilities in our study made average aggregate annual investments of more than $\$ 6.4$ billion per year. This translates into an annual revenue requirement increase per year on the order of $\$ 1$ billion to $\$ 1.5$ billion. This is a significant cost and deserves the attention of regulators and the application of appropriate least-cost strategies. To put this in context, the 124 companies in our study had a total average revenue during the 1995-1999 period of just over \$134 billion.

While the analysis here cannot provide the basis for making individual choices for specific projects, it does clearly demonstrate that there are many opportunities to implement distributed resources in lieu of traditional wires and transformers solutions. This report should provide the regulator with some guidelines about the important aspects of distribution costs and a framework for assessing the avoided costs of the distribution system. 


\section{REPORT DOCUMENTATION PAGE}

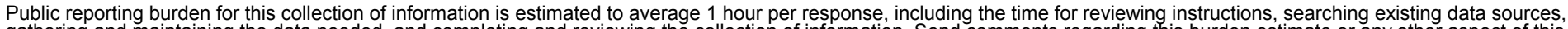

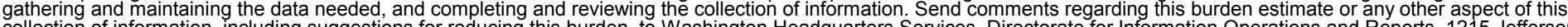
Davis Highway, Suite 1204, Arlington, VA 22202-4302, and to the Office of Management and Budget, Paperwork Reduction Project (0704-0188), Washington, DC 20503.
1. AGENCY USE ONLY (Leave blank)
2. REPORT DATE
October 2002
3. REPORT TYPE AND DATES COVERED Subcontract Report

4. TITLE AND SUBTITLE

State Electricity Regulatory Policy and Distributed Resources:

Distribution System Cost Methodologies for Distributed Generation

6. AUTHOR(S)

W. Shirley, R. Cowart, R. Sedano, F. Weston, C. Harrington, and D. Moskovitz

7. PERFORMING ORGANIZATION NAME(S) AND ADDRESS(ES)

The Regulatory Assistance Project

177 Water Street

Gardiner, Maine 04345

207-582-1135

50 State Street

Montpelier, Vermont 05602

802-223-8199

9. SPONSORING/MONITORING AGENCY NAME(S) AND ADDRESS(ES)

National Renewable Energy Laboratory

1617 Cole Blvd.

Golden, CO 80401-3393

5. FUNDING NUMBERS

CF: NAD-1-30605-03

TA: DP02.1001

8. PERFORMING ORGANIZATION REPORT NUMBER

11. SUPPLEMENTARY NOTES

NREL Technical Monitor: Thomas Basso

12a. DISTRIBUTION/AVAILABILITY STATEMENT

National Technical Information Service

12b. DISTRIBUTION CODE

U.S. Department of Commerce

5285 Port Royal Road

Springfield, VA 22161

13. ABSTRACT (Maximum 200 words)

This report focuses on the actual costs of distribution utilities in the United States. It draws from a number of sources to demonstrate the significant deviation between particular distribution expansion costs and average marginal and average embedded costs. While the analysis here cannot provide the basis for making individual choices for specific projects, it does demonstrate that there are opportunities to implement distributed resources in lieu of traditional wires and transformers solutions. This report should provide the regulator with some guidelines about the important aspects of electricity distribution costs and a framework for assessing the avoided costs of the distribution system.

This report is one in the State Electricity Regulatory Policy and Distributed Resources series developed under contract to NREL (see Annual Technical Status Report of the Regulatory Assistance Project, NREL/SR-560-32733). Other titles in this series are:

- Accommodating Distributed Resources in Wholesale Markets, NREL/SR-560-32497

- Distributed Resource Distribution Credit Pilot Programs - Revealing the Value to Consumers and Vendors, NREL/SR-560-32499

- Distributed Resources and Electric System Reliability, NREL/SR-560-32498

- Distribution System Cost Methodologies for Distributed Generation Appendices, NREL/SR-560-32501.

14. SUBJECT TERMS

distributed energy resources; DER; distributed resources; distributed generation; distributed power; electricity distribution cost; marginal cost; O\&M cost; interconnection; regulatory policy; utility grids; electric industry restructuring; public utility commissions; National Renewable Energy Laboratory; NREL

17. SECURITY CLASSIFICATION OF REPORT Unclassified
18. SECURITY CLASSIFICATION OF THIS PAGE Unclassified
19. SECURITY CLASSIFICATION OF ABSTRACT Unclassified
15. NUMBER OF PAGES

16. PRICE CODE

20. LIMITATION OF ABSTRACT

UL 